\title{
Tatjana Tolstoj: Rijeka Okkervil / S ruskog preveo Petar Karavlah
}

Kako se približavalo doba Škorpiona, postajalo je sve vjetrovitije, tamno i kišovito. Mokri, tekući grad, koji je vjetrom udarao u stakla iza nezaštićenih samačkih prozora bez zavjesa, iza sirnog namaza skrivenog u hladnoći između prozorskih stakala, nalikovao je na podlu Petrovu nakanu, na grad gorostasnog, buljavog cara tesara razjapljene gubice i oštrog jezika, koji u noćnim morama, s mornarskom sjekirom u podignutoj šaci, sustiže svoje onemoćale, prestrašene podanike. Rijeke su se, dotekavši do nabujalog, zastrašujućeg mora, bacale natrag te šišteći probijale okanca od lijevanog željeza i brzinski podizale razinu vode u podrumima muzeja, oblizujući krhke kolekcije koje su se raspršivale u vlažni pijesak, šamanske maske od pijetlova perja, zakrivljene inozemne mačeve, ogrtače opšivene biserima, žilave noge srditih zaposlenika probuđenih usred noći. Na takve dane, kada se iz kiše, mraka i vjetra koji je savijao stakla ocrtavao bijeli sirasti lik samoće, Simeonov je na rubu postojanja postavio čajnik, osjećajući se osobito nosatim, ćelavim, primjećujući svoje godine na licu i jeftine čarape skroz dolje, obrisao je rukavom prašinu sa stola, oslobodio prostor od knjiga koje su isplazile bijele jezičke straničnika, namjestio gramofon, birajući knjigu prikladne debljine koju će podmetnuti pod njega, i veseleći se unaprijed, izvlačio iz istrošenog omota prošaranog žućkastim mrljama Veru Vasiljevnu - stari, teški krug koji se prelijevao antracitnim glatkim koncentričnim krugovima - na svakoj strani po jedna romanca. “Ne, ne tebe! Tako vatreno! Ja! Ljubim!“ poskakujući, pucketajući i šušteći, hitro se vrtjela pod iglom Vera Vasiljevna; šuštanje, krckanje i vrtnja ondulirali su u crnom lijevku, širili se trubom gramofona i slaveći pobjedu nad Simeonovim, noseći iz čipkaste orhideje božanstven, taman, nizak, ispočetka čipkast i prašnjav, zatim nabujao od podvodnog pritiska glas koji se dizao iz dubina, preobražavao se, talasajući se plamenovima na vodi, pš-pš-pš, pš-pš-pš - glas koji je punio jedra, sve glasnije, koji je kidao konopce, neobuzdano se kretao, pš-pš-pš, karavelom po uzavreloj noćnoj vodi - sve jače - razapinjao krila, ubrzavao, gipko se otkidao od ostatka bujice 
koja ga je porodila, od majušnog Simeonova koji je ostao na obali i zabacio proćelavu, golu glavu prema divovskom, blistavom glasu, rođenom iz pobjedonosnog pokliča koji je zatamnio pola neba - ne, nije njega tako vatreno ljubila Vera Vasiljevna, ali svejedno, u suštini, samo njega jedinog, i to im je bilo zajedničko.

\section{H-š-š-š-š-š-š-š-š-š.}

Simeonov je pažljivo skinuo utihlu Veru Vasiljevnu i njihao ploču obuhvativši je ispruženim dlanovima punim poštovanja; promatrao je starinsku naljepnicu: ah, gdje ste sada, Vera Vasiljevna? Gdje su sada vaše bijele koščice? I, prevrnuvši je na leđa, postavio je iglu, žmirkajući od bljeska boje suhe šljive na površini lelujajuće ploče, ponovno je slušao čeznuvši za davno ocvalim, ššš, krizantemama u vrtu, ššš, gdje su se susreli i ponovno je, nadolazeći podzemnom bujicom, zbacujući prašinu, čipku i godine pucketala Vera Vasiljevna podsjećajući na sanjivu najadu - neatletsku, punašnu najadu s početka stoljeća - o slatka kruško, gitaro, kotrljajuća boco šampanjca!

Tada zakipi čajnik te Simeonov izvadi iz prozora sir ili narezanu šunku, ponovno stavi ploču i stane blagovati po samački, na prostrtim novinama, uživajući i radujući se što ga Tamara danas neće uhvatiti, što neće omesti dragocjeni susret s Verom Vasiljevnom. Bilo mu je dobro samome, u malenom stanu, nasamo s Verom Vasiljevnom, s vratima čvrsto zatvorenima od Tamare, krepak i sladak čaj i skoro dovršen prijevod nepotrebne knjige s rijetkog jezika - bit će novaca i Simeonov će kod jednog švercera za velike novce kupiti rijetku ploču na kojoj Vera Vasiljevna tuguje jer proljeće ne dolazi zbog nje - muška romanca, romanca samoće, i pjevat će bestjelesna Vera Vasiljevna, slijevajući se s Simeonovim u jedan tugaljiv, bolan glas. O, blažena samoćo!

Samoća jede iz tavice, izvlači hladan kotlet iz ustajale konzerve, radi čaj na kuhalu - pa što? Mir i sloboda! Obitelj pak zvecka po ormaru za posuđe, postavlja zamke šalicama i tanjurićima, lovi dušu nožem i vilicom - hvata pod rebra s dvije strane - guši je poklopcem za čajnik, nabacuje stolnjak na glavu, dok slobodna samotna duša klizi ispod lanenih resa, puzi poput jegulje kroz prsten za ubruse i - hop! ulovi me! već je tamo, u tamnom, čarobnom krugu ispunjenom vatrom, obrubljena glasom Vere Vasiljevne, optrčava je, prati njezinu suknju i lepezu, iz svijetle plesne dvorane na ljetni balkon u noći, na polukrug iznad vrta s miomirisnim krizantemama, zapravo je njihov bijel, suh i gorak miris, rujanski miris, on nagovještava jesen, rastanak, zaborav, ali ljubav 
još živi u srcu mom bolnom - to je bolestan miris, miris truleži i tuge, gdje ste sada, Vera Vasiljevna, može biti u Parizu ili Šangaju i koja kiša - plava pariška ili žuta kineska - rominja nad vašim grobom i čija zemlja hladi vaše bijele kosti? Ne, ne ljubim tebe tako vatreno! (Govorite! Naravno da mene ljubite.)

Kraj Simeonovljeva prozora prolazili su tramvaji oglašavajući se zvoncem i njišući petljama koje su podsjećale na stremene: Simeonovu se činilo da su u stropu skriveni konji, kao portreti tramvajskih praotaca koje su odnijeli na tavan; zatim je zvonjava utihnula, čuli su se samo udarci, zveket i škripa na zavoju, napokon su poumirali tvrdi crveni vagoni s drvenim klupama te su počeli voziti okrugli, tihi vagoni koji su šumjeli na stanicama, mogli ste sjesti, stropoštati se na meko sjedalo koje je pod vama ispuštalo dušu i otisnuti se u bijeli svijet do posljednje stanice koja je mamila imenom: "Rijeka Okkervil". Ali Simeonov nije nikada bio ondje. Bio je to kraj svijeta i nije imao što ondje raditi, ali nije u tome bila stvar - nikada ne vidjevši tu daleku rijeku koja gotovo da više nije pripadala Lenjingradu, mogao je zamisliti bilo što: mutni zelenkasti potok, na primjer, sa sporim zelenim suncem koje mutno pliva u njemu, srebrnkastim vrbama čije se grane nježno spuštaju s talasaste obale, dvoetažne kuće od crvene cigle s krovovima od crijepa, drvene grbave mostove tih i snen svijet; a u stvarnosti su ondje sigurno skladišta, ograde, neka ružna tvornica koja pljuje sedefasti otrovni otpad, s odlagališta dopire smrdljivi dim truleži ili nešto drugo očajno, periferno i banalno.

Ne treba se razočaravati i ići do rječice Okkervil, bolje je u mislima zasaditi njezine obale dugokosim vrbama, rasporediti kućice strmih krovova, pustiti usporene žitelje, možda s njemačkim šeširima, s prugastim dokoljenkama, s dugačkim porculanskim lulama u zubima... bolje bi bilo popločiti okervilsku obalu, rijeku napuniti čistom sivom vodom, dodati mostove s tornjićima i lancima, poravnati granitni rukohvat šablonom za krivulje, postaviti uzduž obale visoke sive kuće s rešetkama od lijevanog željeza na prolazima - neka vrh kapije bude poput riblje krljušti, a s balkona neka izviruju dragoljubi, onamo treba smjestiti Veru Vasiljevnu i neka šeće po popločenoj obali navlačeći dugu rukavicu, sitno koračajući crnim cipelama s tupim vršcima, peta okruglih poput jabuke, s malenim okruglim šeširom s velom, kroz umuknulu kišicu peterburškog jutra, a u tom slučaju dodati još i plavkastu maglu. 
Dodati plavkastu maglu! Magla je dodana, Vera Vasiljevna prolazi, lupkajući zaobljenim petama, preko čitavog pločnika, tu je granica scene, redatelju je ponestalo sredstava, onemoćao i umoran, on raspušta glumce, briše balkone s dragoljubima, daje rešetku s uzorkom rublje krljušti onima koji je žele, baca u vodu rukohvat, gura u džepove mostove s tornjićima - džepovi se nadimlju, vise lančići kao iz sata nekog djeda - i samo rijeka Okkervil, sužavajući se i šireći, teče i nikako ne može za sebe odabrati neki trajan oblik.

Simeonov je jeo sir, prevodio dosadne knjige, navečer je ponekad dovodio žene, da bi ih ujutro, razočaran, ispraćao - ne, ne tebe! - zatvarao se od Tamare, koja je neprestano dolazila s opranim rubljem, pečenim krumpirom, zavjesama s cvjetnim uzorkom i stalno zaboravljala neke važne stvari kod Simeonova, ukosnicu ili maramicu za nos - pred noć bi joj te stvari postale prijeko potrebne te bi dolazila za njima preko čitavog grada - Simeonov bi ugasio svjetlo i nepomično stajao, stisnuvši se uz vratnicu u hodniku, dok je ona nasrtala - no često je posrtala, i tada je za večeru jeo nešto toplo i pio iz plavo-zlatne šalice jaki čaj uz domaće kroštule, a Tamari je, naravno, bilo prekasno da ide kući, posljednji je tramvaj otišao i ionako ne bi mogao stići do maglovite rijeke Okkervil, tako je Tamara protresala jastuke, dok je Vera Vasiljevna, okrenuvši se leđima, ne slušajući Simeonovljeva opravdanja, po obali nestajala u noć, lelujajući se na petama okruglim poput jabuke.

Jesen se zahuktavala kada je od švercera kupio tešku ploču, izgrebanu s jedne strane - cjenkali su se, prepirući se oko oštećenja, cijena je bila dosta visoka, a zašto? - zato što je Vera Vasiljevna bila sasvim zaboravljena, nećete je čuti ni na radiju, ni u kvizovima neće zabljesnuti njeno nježno prezime, i sada su samo izbirljivi osobenjaci, snobovi, amateri, estete, oni skloni bacanju novca na nematerijalno, jurili za njezinim pločama, nizali ih na klinove gramofona, presnimavali na magnetofon njezin niski, tamni glas koji se presijavao kao vrhunsko crveno vino. No stara je još živa, rekao je švercer, govore da živi negdje u Lenjingradu, u bijedi i prljavštini, a nije dugo sijala u svoje vrijeme, izgubila je briljante, muža, stan, sina, dva ljubavnika i, na kraju, glas - baš tim redom - i uspjela je uz sve te gubitke dogurati do tridesete, i onda prestala pjevati, premda je još uvijek živa.

Tako je to, razmišljao je teška srca Simeonov, i na putu prema kući, preko mostova i vrtova, preko tramvajskih tračnica, nije prestao misliti: tako je to... I tako je, zatvorivši vrata i skuhavši čaj, 
postavio na gramofon pohabano blago i, promatrajući kroz prozor teške cvjetne oblake koji su se skupljali na strani zalaska, podigao kao obično komadić granitne obale, postavio most - tornjići su ovoga puta bili teži - i nepomične lance od lijevanog željeza, a vjetar je nabirao i mreškao, uzburkavao široku sivu površinu rijeke Okkervil, a Vera Vasiljevna, spotičući se više no što bi trebala u petama koje je izmislio Simeonov, skršila je ruke i klonula malenom, glatko počešljanom glavom prema nagnutom ramenu - tiho, tako tiho svijetli luna, a moja glava misli o tebi je puna mjesec se nije dao, kao sapun je klizio iz ruku, prolazio je iza razbacanih okervilskih oblaka - na tom Okkervilu uvijek se nešto događalo s nebom - kako se nemirno miču prozirne, ukroćene sjene naše mašte, kada buka i mirisi žive glazbe prodiru u njihov hladni, magloviti svijet!

Promatrajući rijeke u zalasku iz kojih je izvirala i rijeka Okkervil, koja je već ocvjetala otrovnim zelenilom, već otrovana disanjem žive starice, Simeonov je slušao glasove dvaju sukobljenih demona koji su se svađali: jedan je nastojao izbaciti staru iz glave, zatvoriti čvršće vrata, tu i tamo ih odškrinuti za Tamaru, živjeti kao što je živio prije, ljubeći umjereno, žeznuvši umjereno, u trenucima samoće prepuštajući se zvuku srebrne trube koja je pjevala ponad neznane maglovite rijeke, dok je drugi demon - pomahnitali mladić svijesti pomračene od prevođenja loših knjiga zahtijevao da pođe, potrči u potragu za Verom Vasiljevnom - napola slijepom, bijednom, ispijenom, promuklom isušenom staricom - da je pronađe, prikloni se uz njezino nagluho uho i poviče kroz vremena i nevremena da je ona jedinstvena, da je nju, i samo nju, uvijek volio, da u njegovu bolnom srcu još uvijek ima ljubavi, da je ona prekrasna Peri ${ }^{[1]}$ čiji se glas podiže iz podvodnih dubina, puneći jedra, hitro se povlačeći preko plamenih noćnih voda, kovitlajući se uvis, prekrivši pola neba, uništila ga je i podigla - Simeona, odanog viteza - smlavljeni svojim srebrnim glasom u komadiće su se na sve strane raznijeli tramvaji, knjige, sirni namaz, mokri pločnici, ptičji krici, Tamare, šalice, bezimene žene, godine koje prolaze, sva nepostojanost svijeta. Osupnuta starica pogledala ga je očima punim suza: Kako? Vi me poznajete? Ne može biti! Bože moj! Zar je ikome još stalo? Nikad ne bih rekla! - i zbunivši se, ne bi znala kamo posjesti Simeonova, dok je on pažljivo pridržavao njezin suhi lakat i ljubeći joj ruku koja više nije bila bijela nego prekrivena staračkim pjegama, vodio je do naslonjača, zagledavajući se u njezino ocvalo lice starice. I s nježnošću i sažaljenjem, promatrajući praznine u njezinoj tankoj kosi, mislit će: oh, kako smo se 
mimoišli u ovome svijetu! (“Uf, nemoj!“ - prenemagao se unutarnji demon, no Simeonov nije tako mislio.)

Adresu Vere Vasiljevne nabavio je smiješno jednostavno, za pet kopjejki, u jednoj uličnoj govornici. Srce mu je preskočilo: hoće li biti Okkervil? Naravno da neće. I nije uz obalu. Kupio je krizanteme na tržnici - malene, žute, zamotane u celofan. Već su davno ocvale. A u pekarnici je izabrao kolač.

Prodavačica je, skinuvši plastični poklopac, pružila ruku i pokazala odabrano: može? - ali Simeonov nije obraćao pažnju jer pored prozora je proletjela - ili je to bilo priviđenje? - Tamara, koja je išla po njega u stan, još toploga od sna. Zatim je, već u tramvaju, otvorio kupljeno. Pronjuškao je malo. Ništa posebno. Voćni kolač. Dobro izgleda. U uglovima su spavali usamljeni komadići voća pod staklenastim želeom: tu kriška jabuke, tamo - u malo skupljem uglu - kriška breskve, ovdje pola zamrznute šljive; i još nestašni, damski kutak s tri višnje. Bočne strane posute slastičarskim prahom.

Tramvaj se zatresao, kolač se pomaknuo i Simeonov je na zrcalnoj želatinoznoj površini uočio jasan otisak palca - aljkavog li kuhara, nespretne li prodavačice. Ništa zato, starica loše vidi. Odmah ću ga narezati. ("Vrati se“, sjetno je kimao glavom demon čuvar, "bježi, spašavaj se!"). Simeonov je ponovno zapakirao kutiju najbolje što je mogao i stao promatrati zalazak. Uskim tokom šumio je Okkervil, zapljuskujući granitne obale, obale su se rasipale kao da su od pijeska i puzile u vodu. Stao je pred kućom Vere Vasiljevne premještajući darove iz jedne ruku u drugu. Vrata kroz koja je trebao kročiti bila su ukrašena ribljom krljušti. Iza njih je bilo stravično dvorište. Mačka je šmugnula. Da, to je i mislio. Velika zaboravljena umjetnica trebala bi živjeti upravo u ovakvom dvorištu. Sporedni ulaz, kante za smeće, uski željezni rukohvati, prljavština. Srce mu je lupalo. Davno su usahli. U mom bolnom srcu.

Pozvonio je. ("Glupan!“ pljunuo je unutarnji demon i ostavio Simeonova.) Vrata su se širom otvorila pod naletom buke, pjeva i smijeha koji je briznuo iz kuće i odmah je osvanula Vera Vasiljevna, bijela, golema, narumenjena, crnih i gustih obrva, osvanula je ondje iza postavljenog stola, u osvijetljenoj niši, nad hrpom predjela koja su zamirisala sve do vrata, nad ogromnom čokoladnom tortom ovjenčanom čokoladnim zecom, osvanula je grohotom se smijući - i sudbina ju je odabrala za sva vremena. Petnaest ljudi za stolom smijalo se gledajući joj u usta: Veri Vasiljevnoj bio je rođendan, prepričavala je neku anegdotu gušeći se od smijeha. Počela ju je pričati još dok se 
Simeonov penjao po stubama, prevarila ga je s tom petnaestoricom, još dok se nećkao i premišljao pred vratima prebacujući kolač s greškom iz ruke u ruku, još dok se vozio u tramvaju, još dok se zatvarao u stan i pravio mjesta na prašnjavom stolu za njezin srebrni glas, još kada je prvi puta sa znatiželjom iz požutjelog zgužvanog omota izvadio crni disk s mjesečevim odsjajem, još dok na svijetu nije bilo nikakvog Simeonova, samo je vjetar povijao travu i svijetom je vladala tišina. Nije ga čekala, mršava, kraj uskog prozora, zagledavajući se u daljinu, u staklene struje rijeke Okkervil, prigušeno se smijala nad stolom pretrpanim posuđem, nad salatama, krastavcima, ribom i bocama i odvažno je pila, čarobnica, i odvažno je okretala svoje ugojeno tijelo. Izdala ga je. Ili je on izdao Veru Vasiljevnu? Sada je bilo prekasno za dokučivanje.

"Još jednom!“ poviknuo je netko kroza smijeh, odmah se ispostavilo da se preziva Poljupčev. "Jednu za kaznu!" Simeonovu su oduzeli komad torte s otiskom i cvijeće i ugurali ga za stol da digne čašu u zdravlje Vere Vasiljevne, zdravlje koje je, kako se prisjećao sa zlobom, bila zadnja stvar koja joj je trebala. Simeonov je sjedio, s umjetnim smiješkom, kimao glavom, ciljao vilicom ukiseljenu rajčicu, gledao, kao i svi ostali, u Veru Vasiljevnu i slušao njezine glasne šale - život mu se urušio, prepolovio; sam si kriv, sada ne možeš ništa više učiniti, čak i da pobjegneš; čarobnu divu oteli su zmajevi, sama se s užitkom prepustila otmici, fućkalo joj se za sudbinom predodređenog prekrasnog tužnog proćelavog princa, nije željela čuti njegove korake u šumu kiše i huktanju vjetra izvan jesenskih stakala, nije željela spavati nakon uboda začaranim vretenom, začarana na sto godina, okružila se smrtnim, jestivim ljudima, zbližila se s tim strašnim Poljupčevim - koji je bio još bliži zbog svog prezimena - Simeonov je gazio visoke sive kuće na rijeci Okkervil, rušio mostove s tornjićima i bacao lance, zasuo smećem svjetlosivu vodu, ali rijeka si je ponovno probila korito, a kuće su se uzdigle iz ruševina i po neuništivim mostovima su skakale kočije s upregnutim doratima.

"Imate cigaretu?" upitao je Poljupčev. "Prestao sam, tako da ne nosim sa sobom." Odriješio je Simeonova od pola kutije. "Tko ste vi? Poklonik? To je dobro. Imate svoj stan? S kadom? Gut. Tu ima samo zajednička. Vozit ćete je k sebi na kupanje. Voli se kupati. Prvog u mjesecu se sastajemo, slušamo ploče. Koje imate? "Smaragd“? Šteta. Već je godinama tražimo, ali kao da je u zemlju propala. A te koje vi imate dobro su se prodavale, nisu zanimljive. Imate li možda veze za dimljene kobasice? Ne, njoj ne pašu, to ja sebi... Niste mogli donijeti neko jadnije cvijeće, ha? Ja 
sam donio ruže, velike doslovno kao moja šaka." Poljubčev je pokazao maljavu šaku. "Da vi niste možda novinar? Bilo bi lijepo napraviti emisiju s njom, naša Verica se nada. Kakva njuška. A glas joj je još uvijek kao u đakona. Dajte da zapišem vašu adresu."I tako je, posjevši Simeonova na stolicu svojom velikom rukom - "Sjednite, sjednite, ne treba me ispraćati" - Poljupčev ustao i otišao uzevši Simeonovljev kolač s daktiloskopskim biljegom.

Neki nepoznati ljudi začas su naselili maglovite okervilske obale, vukli za sobom prnje ustajalog mirisa - lonce i madrace, vjedra i riđe mačke - granitna promenada bila je zakrčena, pjevali su svoje pjesme, meli smeće na kaldrmu koju je položio Simeonov, rađali se, množili, išli jedni drugima u goste, debela starica s crnim obrvama ugušila je bljedunjavu sjenu s nagnutim ramenima, nagazila je na šešir s velom, zaškripalo je pod nogama, staromodne zaobljene pete su razbacane u različitim smjerovima, Vera Vasiljevna viknula je preko stola: "Dodajte glive!" $\mathrm{i}$ Simeonov je dodao, a ona je pojela.

Promatrao je kako su joj podrhtavali veliki nos i brkovi ispod njega, kako prelazi s lica na lice svojim velikim crnim očima zahvaćenim staračkom mrenom, tada je netko uključio magnetofon i zaplivao je njezin srebrni glas, skupljajući snagu. "Sve je u redu," mislio je Simeonov. Uskoro ću kući, sve je u redu. Vera Vasiljevna je umrla, davnih dana, ubijena je, raskomadala ju je i pojela ta starica, i koščice su posisane, mogao sam prirediti karmine, ali Poljupčev je odnio tortu, no dobro, evo krizanteme za grob, suho, bolesno, mrtvo cvijeće, nadasve primjereno, izrazio sam poštovanje prema pokojnici, sada mogu ustati i otići.

Oko vrata Simeonovljeva stana motala se Tamara - mila Tamara! - pridržala ga je, uvela unutra, umila, razodjenula i nahranila nečim toplim. Obećao je Tamari da će je ženiti, ali pred jutro, u snu, došla je Vera Vasiljevna, pljunula mu u lice, opsovala ga i otišla u noć po vlažnoj promenadi nabadajući izmišljenim crnim petama. Ujutro je na vrata kucao i zvonio Poljupčev koji je došao provjeriti kupaonicu, pripremiti je za navečer. A navečer je doveo Veru Vasiljevnu da se okupa kod Simeonova, pušio je simeonovljeve cigarete, proždirao sendviče, govorio: "D-a-a... Verica je moćna! Koliko je samo muškaraca proždrla u svoje vrijeme - da ti pamet stane!“ A Simeonov je protiv svoje volje slušao kako se pretilo tijelo Vere Vasiljevne namješta i zapljuskuje u tijesnom koritu kade, kako se njezin mekani, teški, puni bok tare o stijenku kade, kako odvod siše vodu, kako po podu tapkaju bosa stopala i kako se na kraju otključavaju vrata i u kućnom ogrtaču, crvena 
i uparena, izlazi Vera Vasiljevna: "Uh. Fino." Poljupčev je požurio s čajem, a Simeonov je, zatečen i nasmijan, krenuo očistiti za Verom Vasiljevnom, isprati tušem sive ostatke kože s osušenih stijenki kade, pokupiti sijede vlasi iz odvoda. Poljupčev je navio gramofon, sve se jače čuo divan i olujan glas koji se izdizao iz dubina, razapinjući krila, vijući se nad svijetom, nad uparenim tijelom Verice koja je pila čaj s tanjurića, nad Simeonovim koji se pognuo u svojoj doživotnoj poslušnosti, nad toplom domaćicom Tamarom, nad svime čemu nije bilo pomoći, nad nadolazećim zalaskom, nad kišom koja se spremala, nad vjetrom, nad bezimenim rijekama koje su tekle unatrag i izlijevale se preko obala, harajući i poplavljujući grad kako samo rijeke mogu. 
[1] U perzijskoj mitologiji fantastična bića u obliku prekrasnih djevojaka

\section{(c) (i) (요}

Creative Commons Attribution-NonCommercial-NoDerivatives 4.0 International License 